Technical Note

\title{
Automatic identification of activated sludge disturbances and assessment of operational parameters
}

\author{
António L. Amaral ${ }^{\mathrm{a}, \mathrm{b}}$, Daniela P. Mesquita a ${ }^{\text {, Eugénio C. Ferreira }}{ }^{\mathrm{a}, *}$ \\ a IBB-Institute for Biotechnology and Bioengineering, Centre of Biological Engineering, Universidade do Minho, Campus de Gualtar, $4710-057$ Braga, Portugal \\ ${ }^{\mathrm{b}}$ Instituto Superior de Engenharia de Coimbra, Instituto Politécnico de Coimbra, Rua Pedro Nunes, Quinta da Nora, 3030-199 Coimbra, Portugal
}

\section{H I G H L I G H T S}

- Automatic image analysis methodology was evaluated to monitor activated sludge.

- Principal component analysis and decision trees identified different operating conditions.

- Partial least squares estimated sludge volume index and total suspended solids.

- An invaluable method in quality assessment of activated sludge was established.

\section{A R T I C L E I N F O}

\section{Article history:}

Received 20 June 2012

Received in revised form 21 December 2012

Accepted 25 December 2012

Available online 26 January 2013

\section{Keywords:}

Image analysis

Partial least squares

Principal components analysis

Decision trees

Activated sludge

Bulking

\begin{abstract}
A B S T R A C T
Activated sludge systems are prone to be affected by changes in operating conditions leading to problems such as pinpoint flocs formation, filamentous bulking, dispersed growth, and viscous bulking. These problems are often related with the floc structure and filamentous bacteria contents. In this work, a lab-scale activated sludge system was operated sequentially obtaining filamentous bulking, pinpoint floc formation, viscous bulking and normal conditions. Image processing and analysis techniques were used to characterize the contents and structure of aggregated biomass and the contents of filamentous bacteria. Further principal component and decision trees analyses permitted the identification of different conditions from the collected morphological data. Furthermore, a partial least squares analysis allowed to estimate the sludge volume index and suspended solids key parameters. The obtained results show the potential of image analysis procedures, associated with chemometric techniques, in activated sludge systems monitoring.
\end{abstract}

(c) 2013 Elsevier Ltd. All rights reserved.

\section{Introduction}

Wastewater treatment plants (WWTPs) are commonly operated using biological processes which is the case of activated sludge (AS) systems. These are very susceptible processes to unexpected changes in operational conditions, where several disturbances associated to biomass structure and sludge settling ability may arise. Pinpoint flocs formation, filamentous bulking, dispersed growth, and viscous bulking are the most common problems in AS, regarding sludge settling ability. It has been reported in the literature (Wilén and Balmer, 1999; Wilén et al., 2003, 2008) that changing operational conditions mostly affects the solid-liquid separation, a stage that is often characterized by the sludge volume index (SVI), the biomass structure and the mixed liquor suspended solids (MLSS) within the reactor. However, the determination of these operational parameters cannot be performed timely, by con-

\footnotetext{
* Corresponding author. Tel.: +351 253604 407; fax: +351 253604429.

E-mail address: ecferreira@deb.uminho.pt (E.C. Ferreira).
}

ventional analytical procedures, for purposes of real time monitoring.

To overcome the time-consuming analytical procedures, image processing and analysis methodologies have been increasingly used for AS characterization, in order to timely predict these parameters. Based on microscopy inspection, SVI has been shown to be related to the floc structure in AS systems (Palm et al., 1980; Dagot et al., 2001), and filamentous bacteria contents and composition overwhelmingly on filamentous bulking surveys (Lee et al., 1983; da Motta et al., 2001a,b; Jenné et al., 2004, 2007; Amaral and Ferreira, 2005; Mesquita et al., 2009). However, the application of the published models to predict the SVI or MLSS fails to other types of disturbances, since the biomass structure is different for each disturbance. Recently, the works of Mesquita (2011), Mesquita et al. (2011a), and Mesquita et al. (2011b) can be seen as a breakthrough regarding the characterization and identification of the most common AS abnormalities such as pinpoint flocs formation, filamentous bulking and viscous bulking. The knowledge of the disturbance concerning an AS system is crucial 
since the corrective measures depend on the type of the disturbance, and its identification is not straightforward by simply analyzing the SVI or MLSS values. For instance, a value of SVI above $150 \mathrm{~mL} \mathrm{~g}^{-1}$ may point to a bulking problem (Jenkins et al., 2003), but does not gives more information about its origin (either due to excessive filamentous growth in filamentous bulking or to excessive production of extracellular polymers forming large aggregates in viscous bulking). The present study thus aims to extend the knowledge on automatic identification of AS disturbances, by image processing and chemometric techniques and, more importantly, automatically assesses operational parameters, such as SVI and MLSS, for each identified condition.

Following previous studies an overall methodology was put into practice allowing for a fast and accurate prediction of MLSS and SVI operational parameters, taking into account their dependence on each particular operating condition. For that purpose, experiments were conducted in order to obtain filamentous bulking, pinpoint floc formation and viscous bulking conditions apart from the normal operation. The obtained image analysis data were used to identify AS malfunctions (pinpoint flocs formation, filamentous bulking and viscous bulking) by principal components (PCA) and decision trees (DT) analyses, and predict the settling ability (namely SVI) and MLSS parameters by multivariate partial least squares (PLS).

\section{Materials and methods}

\subsection{Experimental setup}

An AS system composed by an aeration tank (17 L) and a clarifier $(2.5 \mathrm{~L})$ was used in this study. The system was equipped with two feed pumps for synthetic wastewater dilution, air supply at the bottom of the aeration tank and sludge recirculation from the clarifier to the aeration tank. The $\mathrm{pH}$ was controlled at 7 with a pH meter (Model 924001, Jenway Scientific, UK) using a control pump (Model BL 7916-BL 7917, Hanna Instruments, Woonsocket, RI, USA) dosing $0.01 \mathrm{M} \mathrm{HCl}$ or $0.01 \mathrm{M} \mathrm{NaOH}$ when the pH was respectively above or below the set point, and the temperature was controlled at room temperature. The system was inoculated with AS from a domestic WWTP located in the North of Portugal. A synthetic wastewater $\left(\mathrm{mg} \mathrm{L}^{-1}\right)$ composed by acetate as the main carbon source was used to perform the experiments and consisted of: $\mathrm{NaCH}_{3} \mathrm{COO} \cdot 3 \mathrm{H}_{2} \mathrm{O}, 2073$; $\left(\mathrm{NH}_{4}\right)_{2} \mathrm{SO}_{4}, 140 ; \mathrm{MgSO}_{4} \cdot 7 \mathrm{H}_{2} \mathrm{O}, 25 ; \mathrm{KH}_{2}$ $\mathrm{PO}_{4}, 44 ; \mathrm{K}_{2} \mathrm{HPO}_{4} \cdot 2 \mathrm{H}_{2} \mathrm{O}, 59 ; \mathrm{CaCl}_{2} \cdot 2 \mathrm{H}_{2} \mathrm{O}, 30 ; \mathrm{FeCl}_{3} \cdot 6 \mathrm{H}_{2} \mathrm{O}, 18.8$; $\mathrm{NaHCO}_{3}, 105$, and $20 \mathrm{~mL}$ of trace element solution for biomass maintenance. The trace element solution $\left(\mathrm{g} \mathrm{L}^{-1}\right)$ used consisted of: $\mathrm{H}_{3} \mathrm{BO}_{3}, 0.05 ; \mathrm{ZnCl}_{2}, 0.05 ; \mathrm{CaI}_{2} \cdot 2 \mathrm{H}_{2} \mathrm{O}, 0.04 ; \mathrm{MnCl}_{2}, 0.02 ;\left(\mathrm{NH}_{4}\right) 6-$ $\mathrm{Mo}_{7} \mathrm{O}_{24} \cdot 4 \mathrm{H}_{2} \mathrm{O}, 0.055 ; \mathrm{AlCl}_{3}, 0.05 ; \mathrm{NiCl} \cdot 6 \mathrm{H}_{2} \mathrm{O}, 0.11$. Four different experimental conditions (pinpoint flocs formation, filamentous bulking, viscous bulking and normal conditions) were attained by changing the ratio food/microorganisms (F/M) and the sludge residence time (SRT). For filamentous and viscous conditions the SRT was maintained at $20 \mathrm{~d}$. For pinpoint flocs and normal conditions experiments, SRT of 15 and $6 \mathrm{~d}$ were used, respectively. For filamentous bulking F/M increased from 0.1 to $0.38 \mathrm{~kg} \mathrm{COD} \mathrm{kg}^{-1}$ MLSS $\mathrm{d}^{-1}$; pinpoint flocs formation were achieved decreasing the $\mathrm{F} / \mathrm{M}$ from 0.2 to $0.02 \mathrm{~kg} \mathrm{COD} \mathrm{kg}^{-1} \mathrm{MLSS} \mathrm{d}^{-1}$, and for the viscous bulking experiment $\mathrm{F} / \mathrm{M}$ increased from 0.02 to $0.2 \mathrm{~kg}$ COD kg-1 MLSS d $\mathrm{d}^{-1}$. Finally, the normal conditions experiment was performed with an $\mathrm{F} / \mathrm{M}$ ranging between 0.13 and $0.15 \mathrm{~kg} \mathrm{COD} \mathrm{kg}^{-1} \mathrm{MLSS} \mathrm{d}^{-1}$.

\subsection{Physicochemical parameters}

System performance was evaluated regularly by measuring the MLSS, SVI, ammonium, nitrite, nitrate, and COD content. The MLSS and SVI measurements were conducted in accordance with the procedures described in Standard Methods, where MLSS was measured by weight and further used to calculate SVI by sludge height variation monitored for $30 \mathrm{~min}$ (APHA, 1989). Samples for $\mathrm{NH}_{4}^{+}$, $\mathrm{NO}_{2}^{-}, \mathrm{NO}_{3}^{-}$, and $\mathrm{COD}$ quantification were collected from the synthetic wastewater and the reactor and filtered. $\mathrm{NH}_{4}^{+}$was determined according to Nessler's method (APHA, 1989). $\mathrm{NO}_{2}^{-}$was determined with Griess-Hosvay method, similar to the colorimetric method from Standard Methods (APHA, 1989). $\mathrm{NO}_{3}^{-}$was determined according to Sarraguça et al. (2009) by HPLC (Jasco, Tokyo, Japan) with automatic injection, UV detector $(210 \mathrm{~nm})$ and a Varian (Palo Alto, CA, USA) Metacarb 67H column operating at room temperature of $60^{\circ} \mathrm{C}$. The eluent was a solution of sulfuric acid

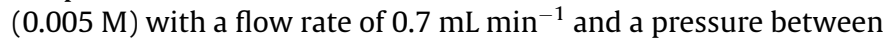
6864 and $7845 \mathrm{kPa}$. COD was measured with Hach Lange COD cell tests (LCK 414 and LCK 514) on a spectrophotometer (Hach Lange DR 5000). The physicochemical SVI and MLSS data was further used for disturbances identification and MLSS and SVI prediction by the image analysis data.

\subsection{Image acquisition and processing}

Samples from each experiment, taken from the aeration tank, were observed in an Olympus BX51 optical microscope (Olympus, Tokyo, Japan), in bright-field at 100x total magnification, coupled with an Olympus DP25 camera (Olympus, Tokyo, Japan). Microbial structure images were acquired at $1360 \times 1024$ pixels and 8-bit format through the commercial software Cell^ $B$ (Olympus, Tokyo, Japan). Three slides per sample were used resulting in a total of 150 images ( $3 \times 50$ images per slide). A sectioned tip recalibrated micropipette was used to deposit samples on the slides. For each slide, a volume of $10 \mu \mathrm{L}$ was covered with a $20 \times 20 \mathrm{~mm}$ cover slip, for visualization and image acquisition. Images were acquired in the upper, middle and bottom of the slide in order to improve the representativeness of the microbial community in the system.

Image processing was performed by a program adapted from previous routines developed by Amaral (2003) and optimized by Mesquita (2011) in Matlab 7.3 (The Mathworks, Natick, USA). The main stages of the program comprise the image pre-treatment, segmentation, and debris elimination steps. A more detailed description of the image processing steps can be found in Mesquita et al. (2010).

The aggregated and filamentous biomass contents and structure (morphology) were assessed in the following manner. Aggregates were classified according to their size, namely the equivalent diameter (Deq) in three classes: small aggregates (Deq $<25 \mu \mathrm{m}$ ); intermediate aggregates $(25 \mu \mathrm{m}<$ Deq $<250 \mu \mathrm{m})$; and large aggregates $($ Deq $>250 \mu \mathrm{m})$. The morphological parameters included the Perimeter (P), Length (L), Form Factor (FF), Convexity (Conv), Solidity (Sol), Eccentricity (Ecc), and Ratio between hole and object area (RelArea) determined for the intermediate (int) and large aggregates (lrg). Furthermore, the Deq, Aggregates area percentage $(\%$ Area) and Aggregates number per volume (AgrNb/Vol) were determined for the small ( $\mathrm{sml})$, int and lrg aggregates. Total aggregate area per volume (TA/Vol), Total filament length per volume (TL/ $\mathrm{Vol})$, Total filament length per total aggregate area (TL/TA) and Ln (TL/TA) were also determined. The morphological parameters definition can be found in Amaral (2003), Mesquita et al. (2009), and Mesquita (2011).

\subsection{Multivariate statistical analysis}

PCA was used for the identification of each studied condition, by plotting the three most important principal components (PCs). The image analysis dataset fed to the PCA did not contain any information regarding the samples condition (filamentous bulking, viscous 
bulking, pinpoint flocs formation or normal conditions) thus being an unclassified dataset.

DT was used for the identification of each studied condition, and definition of the key parameters limits. The image analysis dataset fed to the PCA contained also the information regarding the samples condition (filamentous bulking, viscous bulking, pinpoint flocs formation or normal conditions) thus being a classified dataset.

PLS was used to predict the SVI and MLSS. The overall dataset was first divided into four datasets corresponding to the four studied conditions (filamentous bulking, viscous bulking, pinpoint flocs formation, and normal conditions). Each of these datasets then was divided randomly into a training set (67\% of the observations to calibrate the model) and a validation set (33\% of the observations to validate the final model).

All these multivariate statistical analyses were performed in Matlab 7.3 (The Mathworks, Natick, MA), and a detailed description is provided as Supplementary material.

\section{Results and discussion}

Prior to the classification of the dataset samples into each of the four studied conditions, a PLS analysis was performed for the MLSS and SVI prediction. For this purpose two thirds of the 145 samples in this unclassified dataset were used as training set and the remaining third used as validation set. The obtained results, presented in Fig. 1a and b, permitted the determination of only a fair prediction ability for the SVI prediction $\left(R^{2}\right.$ of 0.903$)$ and an unsatisfactory MLSS prediction ( $R^{2}$ of 0.636$)$. These results clearly state the need for a condition based PLS analysis, in order to increase the prediction ability.

A total of $31,42,33$, and 39 samples were obtained regarding the filamentous bulking, pinpoint flocs formation, viscous bulking, and normal conditions experiments, respectively. For each of these samples a total of 27 uncorrelated morphological parameters were collected. A cross-correlation analysis was employed in order to confirm that no pair of morphological parameters presented an $R^{2}$ cross-correlation value above 0.95 . Table 1 shows the dataset properties in MLSS and SVI obtained for each studied condition. Samples from filamentous bulking condition showed SVI values higher than viscous bulking. According to Novak et al. (1993) and Jobbágy et al. (2002), SVI commonly exhibited higher values (in average) for filamentous bulking rather than viscous bulking conditions and the opposite for MLSS, which is in agreement with the results obtained during the present study. For the pinpoint flocs experiment, SVI remained below the bulking threshold value, and MLSS started with a maximum of $3.9 \mathrm{~g} \mathrm{~L}^{-1}$, and decreased afterwards given aggregates washout. Normal conditions experiment showed SVI values lower than $150 \mathrm{~mL} \mathrm{~g}^{-1}$ and MLSS values within the expected ranges. In Mesquita et al. (2011a) the evolution of these parameters with time can be fully observed.
Table 1

Dataset properties for each studied condition.

\begin{tabular}{llc}
\hline Experimental condition & MLSS $\left(\mathrm{g} \mathrm{L}^{-1}\right)$ & SVI $\left(\mathrm{mL} \mathrm{g}^{-1}\right)$ \\
\hline Filamentous bulking & & \\
Min & 2.33 & 262 \\
Max & 3.73 & 415 \\
Pinpoint flocs & & \\
Min & 0.88 & 53 \\
Max & 3.91 & 96 \\
Viscous bulking & & \\
Min & 1.86 & 82 \\
Max & 4.82 & 484 \\
Normal conditions & & 54 \\
Min & 3.0 & 135 \\
Max & 6.58 & \\
\hline
\end{tabular}

The PCA applied to the normalized data of the operation of the lab-scale AS system (Fig. 2a and b) allowed to clearly identify the filamentous bulking conditions by the second principal component (PC2), and, using the first and third principal components (PC1 and PC3), further identify the pinpoint flocs formation, viscous bulking and normal conditions. Thus, each of the studied condition was identified as belonging to the sub-spaces presented in Fig. 2a and b. A fairly good cluster separation between each of the above conditions was obtained as only one filamentous bulking, one viscous bulking, two pinpoint and four normal conditions samples, did not fell into the respective cluster in the PCA analysis, representing $5.5 \%$ of the total samples.

Fig. 3a-c shows the loadings representing the influence of the variables in each PC. In PC2, the main components responsible for the separation of the filamentous bulking cluster from the remaining, was strongly influenced by the \% Area ${ }_{s m l}$, \% Area int $_{\text {, }}$ TL/Vol, and Ln (TL/TA). PC1 and PC3, responsible for the separation of the remaining clusters, were strongly affected by the \% Area $_{1 \mathrm{rg}}$, Deq $_{\text {int }}, L_{\text {int }}, P_{\text {lrg }}, \mathrm{FF}_{\text {int }}, \mathrm{FF}_{\text {lrg }}$, and $\mathrm{Conv}_{\text {lrg }}$, parameters which are commonly related to aggregates morphology and size characterization.

Upon the study of the experiments dataset by a DT analysis, the PCA results could be further corroborated. In fact, the filamentous bulking samples (Fig. 4a) were found to present larger filament

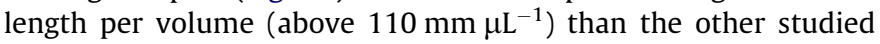
conditions. With respect to the remaining three conditions (Fig. 4b), the pinpoint flocs presented lower intermediate aggregates length (below $98 \mu \mathrm{m}$ ) than the viscous bulking and normal conditions. A third parameter (intermediate aggregates perimeter, $P_{\text {int }}$ ) was then used by the DT analysis to separate between viscous bulking ( $P_{\text {int }}$ above $\left.612 \mu \mathrm{m}\right)$ and normal conditions ( $P_{\text {int }}$ below $612 \mu \mathrm{m})$. Furthermore, the use of the DT analysis allowed to further enhance the identification of each studied condition. In fact only two viscous bulking, one pinpoint and one normal condition samples, did not fell into the respective cluster in the DT analysis, representing $2.8 \%$ of the total samples.
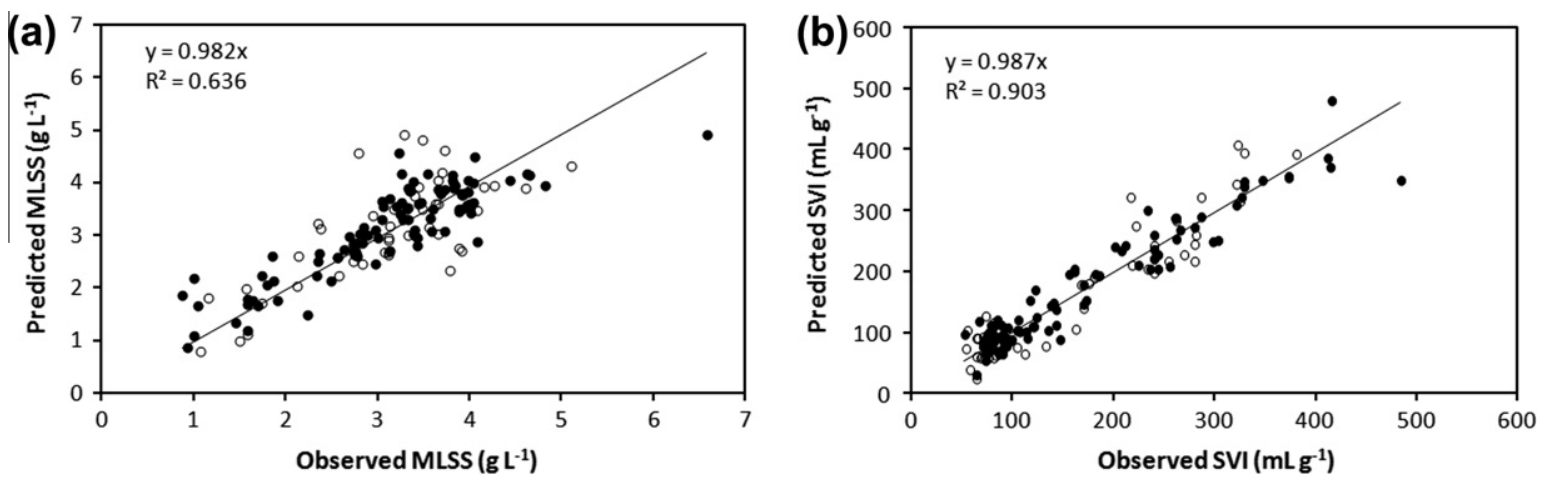

Fig. 1. PLS regression for the unclassified dataset (a) TSS and (b) SVI prediction. Training set (•) Validation set ( $\bigcirc)$. 

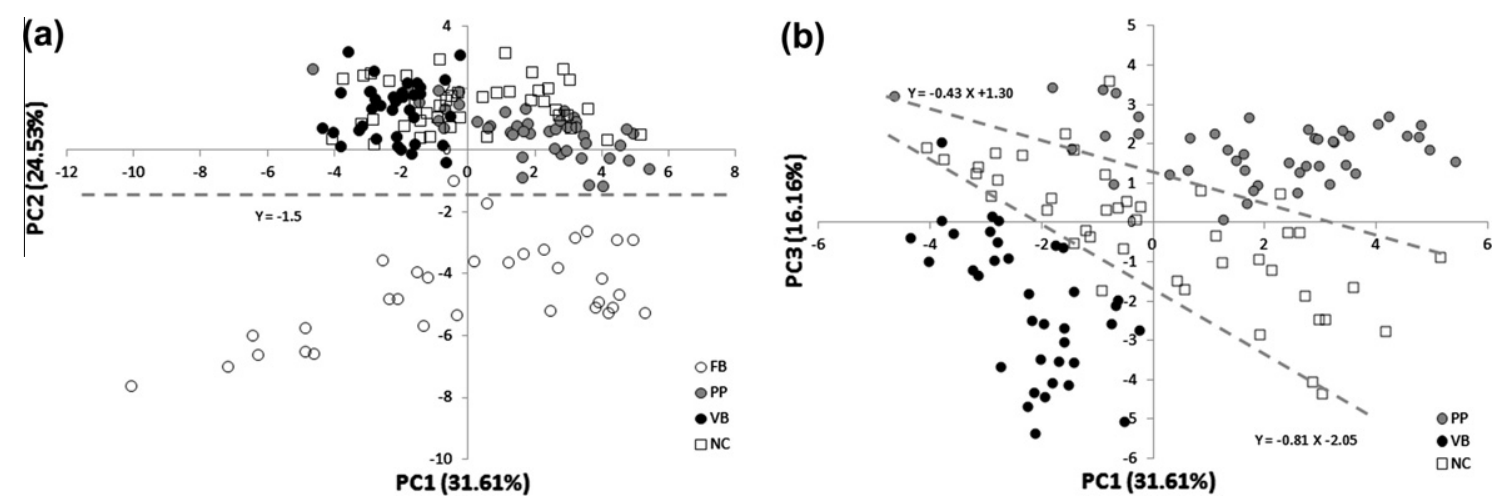

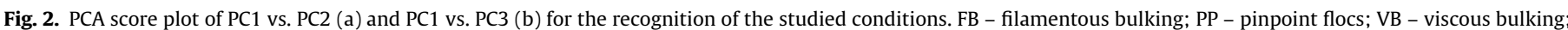
$\mathrm{NC}$ - normal conditions.
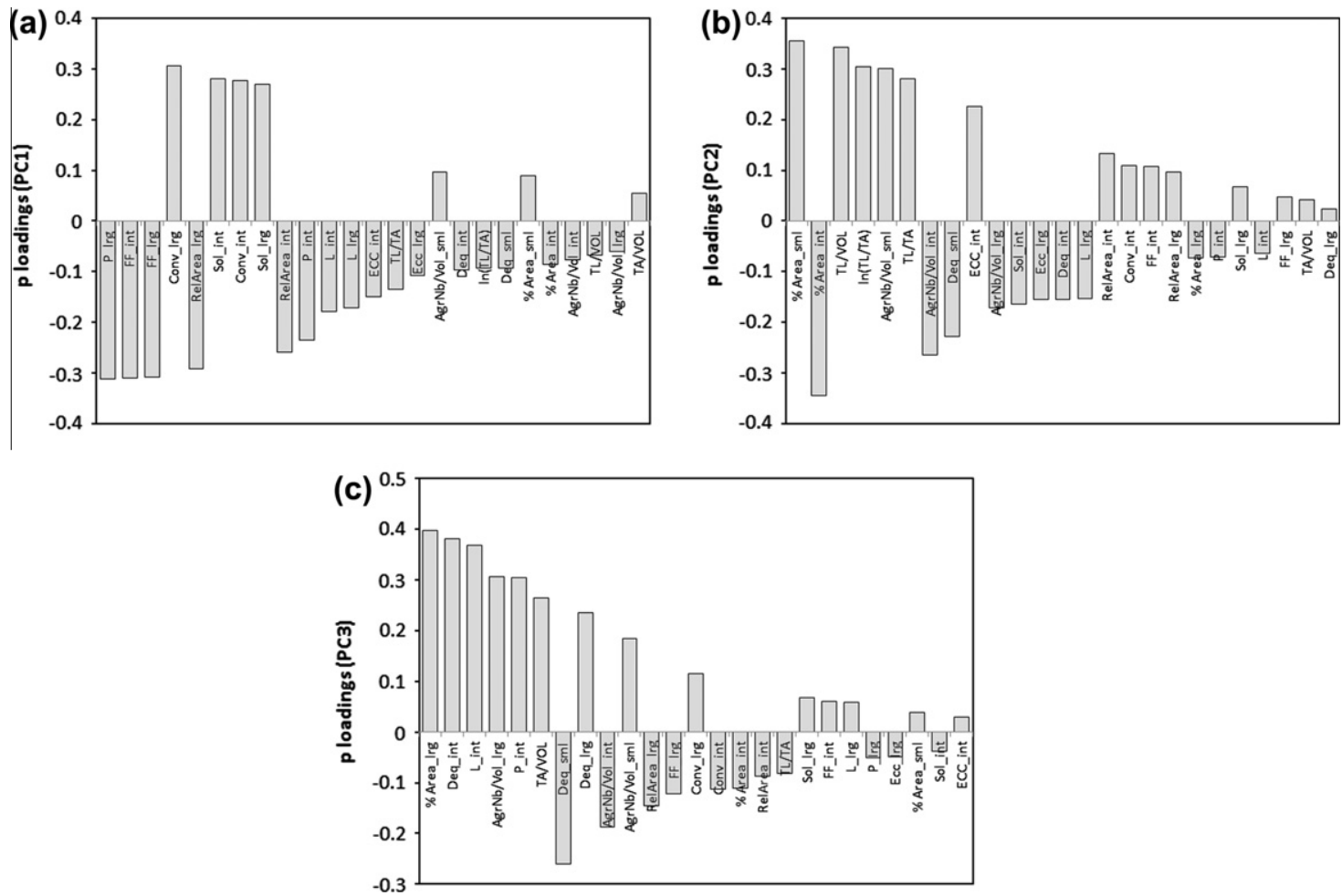

Fig. 3. Loadings representing the influence of the variables in PC1 (a), in PC2 (b), and in PC3 (c).
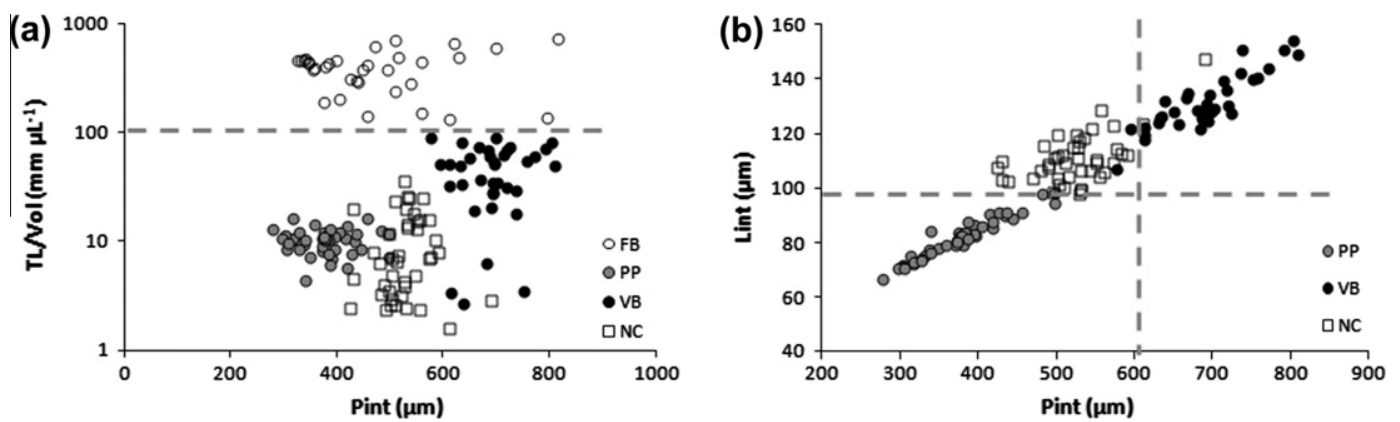

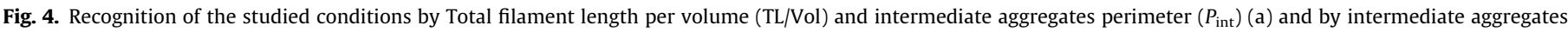
length $\left(L_{\text {int }}\right)$ and perimeter $\left(P_{\text {int }}\right)($ b). FB - filamentous bulking; PP - pinpoint flocs; VB - viscous bulking; NC - normal conditions. 


\section{(a)}
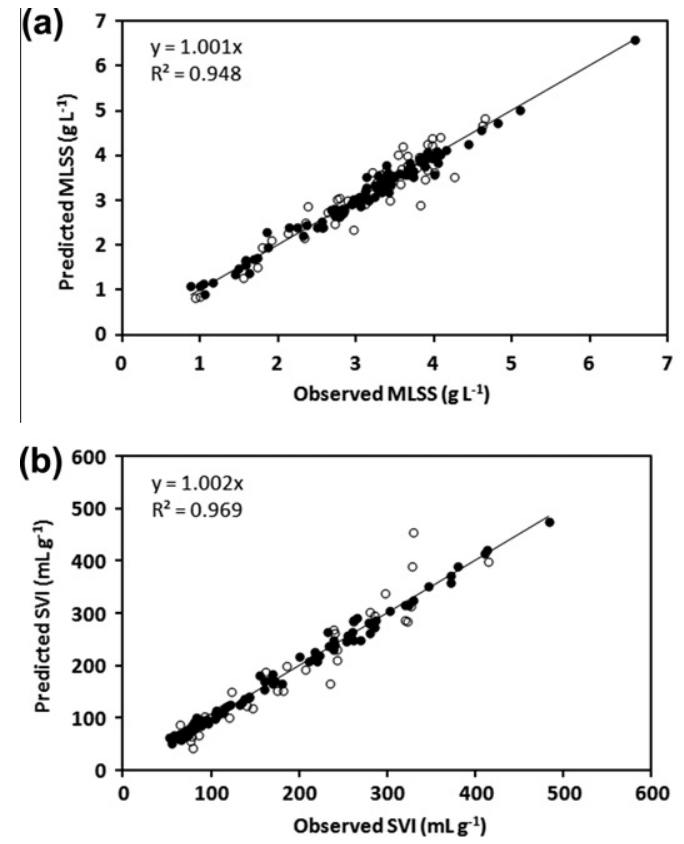

(c)

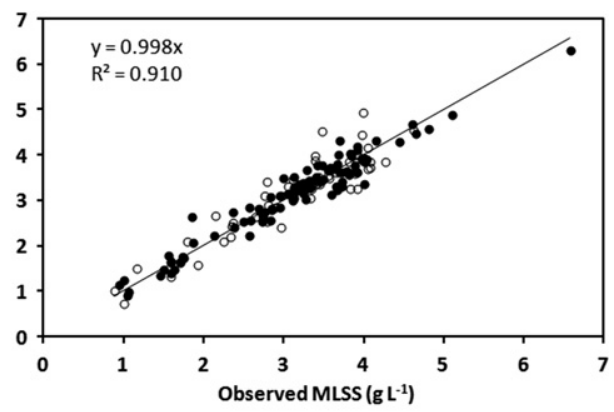

(d)

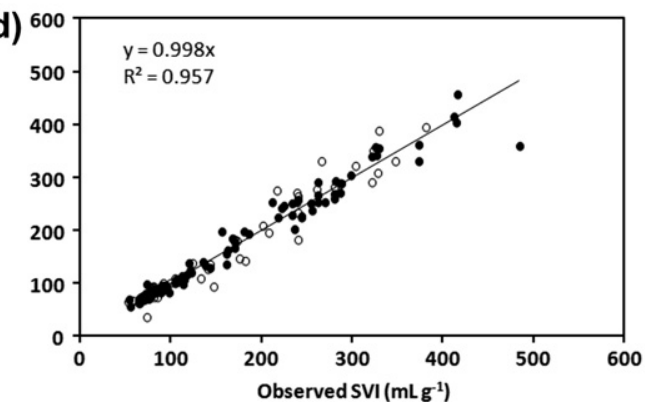

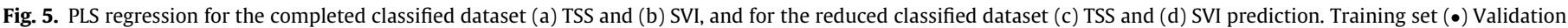
set $(\bigcirc)$.

After the identification of the samples belonging to each condition, an independent PLS analysis was conducted for each of the studied conditions (classified dataset), and the obtained results were compiled in a single graph, containing the overall samples results for the MLSS and SVI prediction (Fig. 5a and b). Good prediction abilities were encountered for both the MLSS $\left(R^{2}\right.$ of 0.948 ) and SVI ( $R^{2}$ of 0.969 ), representing a considerable prediction ability increase regarding to the unclassified dataset.

Furthermore, and in order to avoid possible overfitting problems, the dataset for each condition and model was further reduced to a number of parameters not surpassing half the number of the training samples. These parameters were selected based on their variable importance (VIP) to the model, and thus selected as the parameters presenting the higher VIP value, for the sum of the model latent variables. Once again the obtained results were compiled in an overall graph (Fig. 5c and d). Although the prediction abilities resulting from the reduced dataset were lower than the ones presented by the completed dataset (MLSS $R^{2}$ of 0.910 and SVI $R^{2}$ of 0.958 ), the overall prediction for both MLSS and SVI could be considered as fairly reasonable.

This methodology allowed, thus, for a fairly reasonable prediction of both MLSS and SVI operational parameters, by a fast methodology (about $1 \mathrm{~h}$ to complete the procedure), consuming only a fraction of time required for MLSS (and hence SVI) determination. In this sense, this methodology could be put into practice in WWTP, in order to timely and effectively monitor the AS biomass status and act accordingly to prevent these operational problems, by acting before-hand.

\section{Conclusions}

This work evaluated the feasibility of an automatic image analysis methodology to monitor AS systems. The performed PCA and DT analyses allowed the identification of the filamentous bulking, pinpoint flocs, viscous bulking and normal conditions samples from the collected morphological data, crucial to the selection of the corrective measures. Furthermore, the PLS analysis allowed to reasonably estimate the SVI and MLSS key parameters, given the previous identification of each sample condition, timely for purposes of real time monitoring. In conclusion, these results, obtained in lab-scale experiments, support the use of image analysis procedures in quality assessment of AS systems monitoring and control, for early identification and prevention of operational problems. Nevertheless, future implementation of the presented methodologies in full-scale WWTP is advisable to fully assess their applicability.

\section{Acknowledgements}

The authors acknowledge the financial support to D.P.M. through the post-doctoral grant SFRH/BPD/82558/2011 and to the Project PTDC/EBB-EBI/103147/2008 both funded by Fundação para a Ciência e a Tecnologia (Portugal) and Fundo Social Europeu (FSE).

\section{Appendix A. Supplementary material}

Supplementary data associated with this article can be found, in the online version, at http://dx.doi.org/10.1016/j.chemosphere. 2012.12.066.

\section{References}

Amaral, A.L., 2003. Image analysis in biotechnological processes: applications to wastewater treatment. PhD thesis, Universidade do Minho, Braga, Portugal. $<$ http://hdl.handle.net/1822/4506>.

Amaral, A.L., Ferreira, E.C., 2005. Activated sludge monitoring of a wastewater treatment plant using image analysis and partial least squares regression. Anal. Chim. Acta 544, 246-253.

APHA, 1989. Standard Methods for the Examination of Water and Wastewater. American Public Health Association, Washington, DC

da Motta, M., Amaral, A.L., Casellas, M., Pons, M.N., Dagot, C., Roche, N., Ferreira, E.C., Vivier, H., 2001a. Characterization of Activated Sludge by Automated Image Analysis: Validation on Full-Scale Plants. IFAC Computer Applications in Biotechnology, Québec City, Canada. 427-431.

da Motta, M., Pons, M.N., Roche, N., 2001b. Automated monitoring of activated sludge in a pilot plant using image analysis. Water Sci. Technol. 43 (7), 91-96.

Dagot, C., Pons, M.N., Casellas, M., Guibaud, G., Dollet, P., Baudu, M., 2001. Use of image analysis and rheological studies for the control of settleability of 
710

A.L. Amoral et al./Chemosphere 91 (2013) 705-710

filamentous bacteria: application in SBR reactor. Water Sci. Technol. 43 (3), 2733.

Jenkins, D., Richard, M.G., Daigger, G., 2003. Manual on the Causes and Control of Activated Sludge Bulking, Foaming and Other Solids Separation Problems. Lewis publishing, Bock Rato, FL.

Jenné, R., Banadda, E.N., Stets, I.Y., Deurinck, J., Van Impe, J.F., 2007. Detection of filamentous bulking problems: developing an image analysis system for sludge composition monitoring. Microsc. Microanal. 13, 36-41.

Jenné, R., Banadda, E.N., Stets, I.Y., Van Impe, J.F., 2004. Monitoring activated sludge settling properties using image analysis. Water Sci. Technol. 50 (7), 281-285.

Jobbágy, A., Literáthy, B., Tardy, G., 2002. Implementation of glycogen accumulating bacteria in treating nutrient-deficient wastewater. Water Sci. Technol. 46 (1-2), $185-190$.

Lee, S.E., Koopman, B., Bode, H., Jenkins, D., 1983. Evaluation of alternative sludge settleability indexes. Water Res. 17, 1421-1426.

Mesquite, D.P., 2011. Image analysis and chemometric techniques as monitoring tools to characterize aggregated and filamentous organisms in activated sludge processes. PhD thesis, Universidade do Minho Braga, Portugal. <http:// hdl.handle.net/1822/12470>.

Mesquite, D.P., Amoral, A.L., Ferreira, E.C., 2011a. Identifying different types of bulking in an activated sludge system through quantitative image analysis. Chemosphere 85, 643-652.

Mesquita, D.P., Amoral, A.L., Ferreira, E.C., 2011b. Characterization of activated sludge abnormalities by image analysis and chemometric techniques. Anal. Chin. Acts 705, 235-242.
Mesquita, D.P., Dias, O., Dias, A.M.A., Amaral, A.L., Ferreira, E.C., 2009. Correlation between sludge settling ability and image analysis information using partial least squares. Anal. Shim. Acta 642, 94-101.

Mesquite, D.P., Dias, O., Amoral, A.L., Ferreira, E.C., 2010. A comparison between bright field and phase contrast image analysis techniques in activated sludge morphological characterization. Microsc. Microanal. 16, 166-174.

Novak, L., Larrea, L., Wanner, J., Garcia-Heras, J.L., 1993. Non-filamentous activated sludge bulking in a laboratory scale system. Water Res. 27, 1339-1346.

Palm, J.C., Jenkins, D., Parker, D.S., 1980. Relationship between organic loading, dissolved-oxygen concentration and sludge settleability in the completelymixed activated-sludge process. J. Water Pollute. Control Fed. 52, 2484-2506.

Sarraguça, M.C., Paulo, A., Alves, M.M., Dias, A.M.A., Lopes, J.A., Ferreira, E.C., 2009. Quantitative monitoring of an activated sludge reactor using on-line UV-visible and near-infrared spectroscopy. Anal. Bioanal. Chem. 395, 1159-1166.

Wilén, B.M., Balmer, P., 1999. The effect of dissolved oxygen concentration on the structure, size and size distribution of activated sludge flocs. Water Res. 33, 391-400.

Wilén, B.M., Jun, B., Lent, P., 2003. The influence of key chemical constituents in activated sludge on surface and flocculating properties. Water Res. 37, 21272139.

Wilén, B.M., Lumley, D., Mattsson, A., Minor, T., 2008. Relationship between floc composition and flocculation and settling properties studied at a full scale activated sludge plant. Water Res. 42, 4404-4418. 